\title{
Correction to: Children's affectionate and assertive attitudes towards their parents: the Oedipus complex or parent-offspring conflict?
}

\section{Kutlu Kağan Türkarslan ${ }^{1}$}

Published online: 20 July 2021

(c) Springer Science+Business Media, LLC, part of Springer Nature 2021

\section{Correction to: Integrative Psychological and Behavioral Science https://doi.org/10.1007/s12124-021-09624-w}

The original version of this article unfortunately has errors and should be corrected.

In section "Freud's Oedipus Complex", the first letter of the word Oedipal should be changed to lowercase.

He even argued that fundamental oedipal experiences were partly inherited as a-priori categories $(1918$, p. 87)

In section "Parent-Offspring Conflict", the second to the last sentence of the first paragraph should read:

On the other hand, the parents try hard to balance their reproductive success coming from parental investment and mating efforts.

The first three sentences of the second paragraph under the same section should read:

Parent-offspring conflict is evident in many aspects of human life, from fetal development to mate choices of the offspring (Andrews, 2006; Apostolou, 2007a, 2007b; Fouts et al., 2005; Haig, 1993; Schlomer et al., 2010). As Schlomer et al. stressed (2011), parent-offspring conflict does not have to be an observable behavioral conflict involving of fighting or arguing. In his seminal paper, Trivers (1974) was well aware of the issue and thought that parent-offspring conflict also operates in the psychological sphere "with psychological weapons", especially in early childhood.

The online version of the original article can be found at https://doi.org/10.1007/s12124-021-09624-w

Kutlu Kağan Türkarslan

kutlu.turkarslan@metu.edu.tr

1 Department of Psychology, Middle East Technical University, Çankaya, 06800 Ankara, Turkey 
In section "Configurations of Parent-Offspring Conflict and Sibling Competition", the first sentence should read:

Considering complex relationships that can be formed between familial members, I propose that parent-offspring conflict can be analyzed in three different but related configurations.

In section "Direct Sibling Competition, Early Jealousy, and Oedipal-Like Behaviors", the third sentence of the sixth paragraph should read:

There is nothing more reasonable for a firstborn to exhibit heightened jealousy for their parents if we acknowledge the overlap between the timing of the Oedipus complex and the birth of a sibling.

In section "Indirect Sibling Competition, Primal Scene, and Oedipal-Like Behaviors", the first sentence should read:

If we consider parent-offspring conflict, it is reasonable to anticipate psychological conflicts in the offspring related to the production of future siblings.

In section "Infanticide and Oedipal-Like Behaviors", the first sentence of the second paragraph should read:

Resnick (1969) listed the main reasons for infanticide as fatal maltreatment (lack of parental investment), partner revenge (punishing the partner by killing offspring), unwanted child (reproductive planning), altruistic motive(thinking that death is for the offspring's own sake), and acutely psychotic parent.

In the same section, the last sentence of the past paragraph should read:

As a result, oedipal-like sex contingent relational settings (mother/son or father/ daughter) and affectionate or aggressive expressions may emerge in the family due to the offspring's protection strategy.

In section "What about Only Children and Last-borns?", the fourth sentence of the second paragraph should read:

Total fertility rates do not indicate the exact number of offspring a family has but offers a good estimate.

In the "Conclusion" section, the first sentence should read:

As Daly and Wilson (1990) meticulously examined, parent-offspring conflict is not a sex contingent phenomenon, meaning that the conflicts can occur between both mother-son/father-daughter dyads as well as between mother-daughter/ father-son dyads. 
In the same section, third sentence of the second paragraph should read:

Understanding oedipal-like behaviors from the point of parent-offspring conflict requires consideration of several factors affecting parent-offspring conflict and sibling competition.

The $2^{\text {nd }}$ and $3^{\text {rd }}$ points in the third paragraph of the Conclusion should be:

2) Children's behaviors and attitudes towards the parent, after they sense or learn about an incoming sibling.

3) Changes in children's behaviors or attitudes towards their parents after the birth of a sibling.

Still under the "Conclusion" section, second sentence of the fourth paragraph should read:

Moreover, the studies must control for the effects of variables related to parentoffspring conflict.

The original article has been updated.

Publisher's note Springer Nature remains neutral with regard to jurisdictional claims in published maps and institutional affiliations. 